\title{
EFFICIENT MARKETS HYPOTHESIS
}

\section{Andrew W. Lo}

To appear in L. Blume and S. Durlauf, The New Palgrave: A Dictionary of Economics, Second Edition, 2007. New York: Palgrave McMillan.

\begin{abstract}
The efficient markets hypothesis (EMH) maintains that market prices fully reflect all available information. Developed independently by Paul A. Samuelson and Eugene F. Fama in the 1960s, this idea has been applied extensively to theoretical models and empirical studies of financial securities prices, generating considerable controversy as well as fundamental insights into the price-discovery process. The most enduring critique comes from psychologists and behavioural economists who argue that the EMH is based on counterfactual assumptions regarding human behaviour, that is, rationality. Recent advances in evolutionary psychology and the cognitive neurosciences may be able to reconcile the EMH with behavioural anomalies.
\end{abstract}

There is an old joke, widely told among economists, about an economist strolling down the street with a companion. They come upon a $\$ 100$ bill lying on the ground, and as the companion reaches down to pick it up, the economist says, 'Don't bother - if it were a genuine \$100 bill, someone would have already picked it up’. This humorous example of economic logic gone awry is a fairly accurate rendition of the efficient markets hypothesis $(\mathrm{EMH})$, one of the most hotly contested propositions in all the social sciences. It is disarmingly simple to state, has far-reaching consequences for academic theories and business practice, and yet is surprisingly resilient to empirical proof or refutation. Even after several decades of research and literally thousands of published studies, economists have not yet reached a consensus about whether markets - particularly financial markets - are, in fact, efficient.

The origins of the EMH can be traced back to the work of two individuals in the 1960s: Eugene F. Fama and Paul A. Samuelson. Remarkably, they independently developed the same basic notion of market efficiency from two rather different research agendas. These differences would propel the them along two distinct trajectories leading to several other breakthroughs and milestones, all originating from their point of intersection, the EMH. 
Like so many ideas of modern economics, the EMH was first given form by Paul Samuelson (1965), whose contribution is neatly summarized by the title of his article: 'Proof that Properly Anticipated Prices Fluctuate Randomly’. In an informationally efficient market, price changes must be unforecastable if they are properly anticipated, that is, if they fully incorporate the information and expectations of all market participants. Having developed a series of linear-programming solutions to spatial pricing models with no uncertainty, Samuelson came upon the idea of efficient markets through his interest in temporal pricing models of storable commodities that are harvested and subject to decay. Samuelson's abiding interest in the mechanics and kinematics of prices, with and without uncertainty, led him and his students to several fruitful research agendas including solutions for the dynamic assetallocation and consumption-savings problem, the fallacy of time diversification and logoptimal investment policies, warrant and option-pricing analysis and, ultimately, the Black and Scholes (1973) and Merton (1973) option-pricing models.

In contrast to Samuelson's path to the EMH, Fama's (1963; 1965a; 1965b, 1970) seminal papers were based on his interest in measuring the statistical properties of stock prices, and in resolving the debate between technical analysis (the use of geometric patterns in price and volume charts to forecast future price movements of a security) and fundamental analysis (the use of accounting and economic data to determine a security's fair value). Among the first to employ modern digital computers to conduct empirical research in finance, and the first to use the term 'efficient markets’ (Fama, 1965b), Fama operationalized the EMH hypothesis - summarized compactly in the epigram 'prices fully reflect all available information' - by placing structure on various information sets available to market participants. Fama's fascination with empirical analysis led him and his students down a very different path from Samuelson's, yielding significant methodological and empirical contributions such as the event study, numerous econometric tests of single- and multi-factor linear asset-pricing models, and a host of empirical regularities and anomalies in stock, bond, currency and commodity markets.

The EMH's concept of informational efficiency has a Zen-like, counter-intuitive flavour to it: the more efficient the market, the more random the sequence of price changes generated by such a market, and the most efficient market of all is one in which price changes are completely random and unpredictable. This is not an accident of nature, but is in fact the direct result of many active market participants attempting to profit from their information. Driven by profit opportunities, an army of investors pounce on even the smallest informational advantages at their disposal, and in doing so they incorporate their information 
into market prices and quickly eliminate the profit opportunities that first motivated their trades. If this occurs instantaneously, which it must in an idealized world of 'frictionless' markets and costless trading, then prices must always fully reflect all available information. Therefore, no profits can be garnered from information-based trading because such profits must have already been captured (recall the $\$ 100$ bill on the ground). In mathematical terms, prices follow martingales.

Such compelling motivation for randomness is unique among the social sciences and is reminiscent of the role that uncertainty plays in quantum mechanics. Just as Heisenberg's uncertainty principle places a limit on what we can know about an electron's position and momentum if quantum mechanics holds, this version of the EMH places a limit on what we can know about future price changes if the forces of economic self-interest hold.

A decade after Samuelson’s (1965) and Fama’s (1965a; 1965b; 1970) landmark papers, many others extended their framework to allow for risk-averse investors, yielding a 'neoclassical' version of the EMH where price changes, properly weighted by aggregate marginal utilities, must be unforecastable (see, for example, LeRoy, 1973; M. Rubinstein, 1976; and Lucas, 1978). In markets where, according to Lucas (1978), all investors have 'rational expectations', prices do fully reflect all available information and marginal-utilityweighted prices follow martingales. The EMH has been extended in many other directions, including the incorporation of non-traded assets such as human capital, state-dependent preferences, heterogeneous investors, asymmetric information, and transactions costs. But the general thrust is the same: individual investors form expectations rationally, markets aggregate information efficiently, and equilibrium prices incorporate all available information instantaneously.

\section{The random walk hypothesis}

The importance of the EMH stems primarily from its sharp empirical implications many of which have been tested over the years. Much of the EMH literature before LeRoy (1973) and Lucas (1978) revolved around the random walk hypothesis (RWH) and the martingale model, two statistical descriptions of unforecastable price changes that were initially taken to be implications of the EMH. One of the first tests of the RWH was developed by Cowles and Jones (1937), who compared the frequency of sequences and reversals in historical stock returns, where the former are pairs of consecutive returns with the same sign, and the latter are pairs of consecutive returns with opposite signs. Cootner (1962; 1964), Fama (1963; 1965a), Fama and Blume (1966), and Osborne (1959) perform related tests of the RWH and, 
with the exception of Cowles and Jones (who subsequently acknowledged an error in their analysis - Cowles, 1960), all of these articles indicate support for the RWH using historical stock price data.

More recently, Lo and MacKinlay (1988) exploit the fact that return variances scale linearly under the RWH - the variance of a two-week return is twice the variance of a oneweek return if the RWH holds - and construct a variance ratio test which rejects the RWH for weekly US stock returns indexes from 1962 to 1985. In particular, they find that variances grow faster than linearly as the holding period increases, implying positive serial correlation in weekly returns. Oddly enough, Lo and MacKinlay also show that individual stocks generally do satisfy the RWH, a fact that we shall return to below.

French and Roll (1986) document a related phenomenon: stock return variances over weekends and exchange holidays are considerably lower than return variances over the same number of days when markets are open. This difference suggests that the very act of trading creates volatility, which may well be a symptom of Black’s (1986) noise traders.

For holding periods much longer than one week - fcor example, three to five years Fama and French (1988) and Poterba and Summers (1988) find negative serial correlation in US stock returns indexes using data from 1926 to 1986. Although their estimates of serial correlation coefficients seem large in magnitude, there is insufficient data to reject the RWH at the usual levels of significance. Moreover, a number of statistical artifacts documented by Kim, Nelson and Startz (1991) and Richardson (1993) cast serious doubt on the reliability of these longer-horizon inferences.

Finally, Lo (1991) considers another aspect of stock market prices long thought to have been a departure from the RWH: long-term memory. Time series with long-term memory exhibit an unusually high degree of persistence, so that observations in the remote past are non-trivially correlated with observations in the distant future, even as the time span between the two observations increases. Nature's predilection towards long-term memory has been well-documented in the natural sciences such as hydrology, meteorology, and geophysics, and some have argued that economic time series must therefore also have this property.

However, using recently developed statistical techniques, Lo (1991) constructs a test for long-term memory that is robust to short-term correlations of the sort uncovered by Lo and MacKinlay (1988), and concludes that, despite earlier evidence to the contrary, there is little support for long-term memory in stock market prices. Departures from the RWH can be fully explained by conventional models of short-term dependence. 


\section{Variance bounds tests}

Another set of empirical tests of the EMH starts with the observation that in a world without uncertainty the market price of a share of common stock must equal the present value of all future dividends, discounted at the appropriate cost of capital. In an uncertain world, one can generalize this dividend-discount model or present-value relation in the natural way: the market price equals the conditional expectation of the present value of all future dividends, discounted at the appropriate risk-adjusted cost of capital, and conditional on all available information. This generalization is explicitly developed by Grossman and Shiller (1981).

LeRoy and Porter (1981) and Shiller (1981) take this as their starting point in comparing the variance of stock market prices to the variance of ex post present values of future dividends. If the market price is the conditional expectation of present values, then the difference between the two, that is, the forecast error, must be uncorrelated with the conditional expectation by construction. But this implies that the variance of the ex post present value is the sum of the variance of the market price (the conditional expectation) and the variance of the forecast error. Since volatilities are always non-negative, this variance decomposition implies that the variance of stock prices cannot exceed the variance of ex post present values. Using annual US stock market data from various sample periods, LeRoy and Porter (1981) and Shiller (1981) find that the variance bound is violated dramatically. Although LeRoy and Porter are more circumspect about the implications of such violations, Shiller concludes that stock market prices are too volatile and the EMH must be false.

These two papers ignited a flurry of responses which challenged Shiller's controversial conclusion on a number of fronts. For example, Flavin (1983), Kleidon (1986), and Marsh and Merton (1986) show that statistical inference is rather delicate for these variance bounds, and that, even if they hold in theory, for the kind of sample sizes Shiller uses and under plausible data-generating processes the sample variance bound is often violated purely due to sampling variation. These issues are well summarized in Gilles and LeRoy (1991) and Merton (1987).

More importantly, on purely theoretical grounds Marsh and Merton (1986) and Michener (1982) provide two explanations for violations of variance bounds that are perfectly consistent with the EMH. Marsh and Merton (1986) show that if managers smooth dividends - a well-known empirical phenomenon documented in several studies of dividend policy and if earnings follow a geometric random walk, then the variance bound is violated in theory, in which case the empirical violations may be interpreted as support for this version of the EMH. 
Alternatively, Michener constructs a simple dynamic equilibrium model along the lines of Lucas (1978) in which prices do fully reflect all available information at all times but where individuals are risk averse, and this risk aversion is enough to cause the variance bound to be violated in theory as well.

These findings highlight an important aspect of the EMH that had not been emphasized in earlier studies: tests of the EMH are always tests of joint hypotheses. In particular, the phrase 'prices fully reflect all available information' is a statement about two distinct aspects of prices: the information content and the price formation mechanism. Therefore, any test of this proposition must concern the kind of information reflected in prices, and how this information comes to be reflected in prices.

Apart from issues regarding statistical inference, the empirical violation of variance bounds may be interpreted in many ways. It may be a violation of $\mathrm{EMH}$, or a sign that investors are risk averse, or a symptom of dividend smoothing. To choose among these alternatives, more evidence is required.

\section{Overreaction and underreaction}

A common explanation for departures from the EMH is that investors do not always react in proper proportion to new information. For example, in some cases investors may overreact to performance, selling stocks that have experienced recent losses or buying stocks that have enjoyed recent gains. Such overreaction tends to push prices beyond their 'fair' or 'rational' market value, only to have rational investors take the other side of the trades and bring prices back in line eventually. An implication of this phenomenon is price reversals: what goes up must come down, and vice versa. Another implication is that contrarian investment strategies - strategies in which 'losers' are purchased and 'winners' are sold - will earn superior returns.

Both of these implications were tested and confirmed using recent US stock market data. For example, using monthly returns of New York Stock Exchange (NYSE) stocks from 1926 to 1982, DeBondt and Thaler (1985) document the fact that the winners and losers in one 36-month period tend to reverse their performance over the next 36-month period. Curiously, many of these reversals occur in January (see the discussion below on the 'January effect'). Chopra, Lakonishok and Ritter (1992) reconfirm these findings after correcting for market risk and the size effect. And Lehmann (1990) shows that a zero-net-investment strategy in which long positions in losers are financed by short positions in winners almost always yields positive returns for monthly NYSE/AMEX stock returns data from 1962 to 
1985.

However, Chan (1988) argues that the profitability of contrarian investment strategies cannot be taken as conclusive evidence against the EMH because there is typically no accounting for risk in these profitability calculations (although Chopra, Lakonishok and Ritter, 1992 do provide risk adjustments, their focus was not on specific trading strategies). By risk-adjusting the returns of a contrarian trading strategy according to the capital asset pricing model, Chan (1988) shows that the expected returns are consistent with the EMH.

Moreover, Lo and MacKinlay (1990c) show that at least half of the profits reported by Lehmann (1990) are not due to overreaction but rather the result of positive crossautocorrelations between stocks. For example, suppose the returns of two stocks A and B are both serially uncorrelated but are positively cross-autocorrelated. The lack of serial correlation implies no overreaction (which is characterized by negative serial correlation), but positive cross-autocorrelations yields positive expected returns to contrarian trading strategies. The existence of several economic rationales for positive cross-autocorrelation that are consistent with EMH suggests that the profitability of contrarian trading strategies is not sufficient evidence to conclude that investors overreact.

The reaction of market participants to information contained in earnings announcements also has implications for the EMH. In one of the earliest studies of the information content of earnings, Ball and Brown (1968) show that up to 80 per cent of the information contained in the earnings 'surprises' is anticipated by market prices.

However, the more recent article by Bernard and Thomas (1990) argues that investors sometimes underreact to information about future earnings contained in current earnings. This is related to the 'post-earnings announcement drift' puzzle first documented by Ball and Brown (1968), in which the information contained in earnings announcement takes several days to become fully impounded into market prices. Although such effects are indeed troubling for the EMH, their economic significance is often questionable - while they may violate the EMH in frictionless markets, very often even the smallest frictions - for example, positive trading costs, taxes - can eliminate the profits from trading strategies designed to exploit them.

\section{Anomalies}

Perhaps the most common challenge to the EMH is the anomaly, a regular pattern in an asset's returns which is reliable, widely known, and inexplicable. The fact that the pattern is regular and reliable implies a degree of predictability, and the fact that the regularity is 
widely known implies that many investors can take can advantage of it.

For example, one of the most enduring anomalies is the 'size effect', the apparent excess expected returns that accrue to stocks of small-capitalization companies - in excess of their risks - which was first discovered by Banz (1981). Keim (1983), Roll (1983), and Rozeff and Kinney (1976) document a related anomaly: small capitalization stocks tend to outperform large capitalization stocks by a wide margin over the turn of the calendar year. This so-called 'January effect' seems robust to sample period, and is difficult to reconcile with the EMH because of its regularity and publicity. Other well-known anomalies include the Value Line enigma (Copeland and Mayers, 1982), the profitability of short-term returnreversal strategies in US equities (Rosenberg, Reid and Lanstein,1985; Chan, 1988; Lehmann, 1990; and Lo and MacKinlay, 1990c), the profitability of medium-term momentum strategies in US equities (Jegadeesh, 1990; Chan, Jegadeesh and Lakonishok, 1996; and Jegadeesh and Titman, 2001), the relation between price/earnings ratios and expected returns (Basu, 1977), the volatility of orange juice futures prices (Roll, 1984), and calendar effects such as holiday, weekend, and turn-of-the-month seasonalities (Lakonishok and Smidt, 1988).

What are we to make of these anomalies? On the one hand, their persistence in the face of public scrutiny seems to be a clear violation of the EMH. After all, most of these anomalies can be exploited by relatively simple trading strategies, and, while the resulting profits may not be riskless, they seem unusually profitable relative to their risks (see, especially, Lehmann, 1990).

On the other hand, EMH supporters might argue that such persistence is in fact evidence in favour of EMH or, more to the point, that these anomalies cannot be exploited to any significant degree because of factors such as risk or transactions costs. Moreover, although some anomalies are currently inexplicable, this may be due to a lack of imagination on the part of academics, not necessarily a violation of the EMH. For example, recent evidence suggests that the January effect is largely due to 'bid-ask bounce', that is, closing prices for the last trading day of December tend to be at the bid price and closing prices for the first trading day of January tend to be at the ask price. Since small-capitalization stocks are also often low-price stocks, the effects of bid-ask bounce in percentage terms are much more pronounced for these stocks - a movement from bid to ask for a $\$ 5.00$ stock on the NYSE (where the minimum bid-ask spread was $\$ 0.125$ prior to decimalization in 2000) represents a 2.5 per cent return.

Whether or not one can profit from anomalies is a question unlikely to be settled in an 
academic setting. While calculations of 'paper' profits of various trading strategies come easily to academics, it is virtually impossible to incorporate in a realistic manner important features of the trading process such as transactions costs (including price impact), liquidity, rare events, institutional rigidities and non-stationarities. The economic value of anomalies must be decided in the laboratory of actual markets by investment professionals, over long periods of time, and even in these cases superior performance and simple luck are easily confused.

In fact, luck can play another role in the interpretation of anomalies: it can account for anomalies that are not anomalous. Regular patterns in historical data can be found even if no regularities exist, purely by chance. Although the likelihood of finding such spurious regularities is usually small (especially if the regularity is a very complex pattern), it increases dramatically with the number of 'searches' conducted on the same set of data. Such data-snooping biases are illustrated in Brown et al. (1992) and Lo and MacKinlay (1990b) even the smallest biases can translate into substantial anomalies such as superior investment returns or the size effect.

\section{Behavioural critiques}

The most enduring critiques of the EMH revolve around the preferences and behaviour of market participants. The standard approach to modelling preferences is to assert that investors optimize additive time-separable expected utility functions from certain parametric families for example, constant relative risk aversion. However, psychologists and experimental economists have documented a number of departures from this paradigm, in the form of specific behavioural biases that are ubiquitous to human decision-making under uncertainty, several of which lead to undesirable outcomes for an individual's economic welfare - for example, overconfidence (Fischoff and Slovic, 1980; Barber and Odean, 2001; Gervais and Odean, 2001), overreaction (DeBondt and Thaler, 1985), loss aversion (Kahneman and Tversky, 1979; Shefrin and Statman, 1985; Odean, 1998), herding (Huberman and Regev, 2001), psychological accounting (Tversky and Kahneman, 1981), miscalibration of probabilities (Lichtenstein, Fischoff and Phillips, 1982), hyperbolic discounting (Laibson, 1997), and regret (Bell, 1982). These critics of the EMH argue that investors are often - if not always - irrational, exhibiting predictable and financially ruinous behaviour.

To see just how pervasive such behavioural biases can be, consider the following example which is a slightly modified version of an experiment conducted by two psychologists, Kahneman and Tversky (1979). Suppose you are offered two investment 
opportunities, A and B: A yields a sure profit of $\$ 240,000$, and B is a lottery ticket yielding \$1 million with a 25 per cent probability and \$0 with 75 per cent probability. If you had to choose between A and B, which would you prefer? Investment B has an expected value of $\$ 250,000$, which is higher than A’s payoff, but this may not be all that meaningful to you because you will receive either \$1 million or zero. Clearly, there is no right or wrong choice here; it is simply a matter of personal preferences. Faced with this choice, most subjects prefer A, the sure profit, to B, despite the fact that B offers a significant probability of winning considerably more. This behaviour is often characterized as 'risk aversion' for obvious reasons. Now suppose you are faced with another two choices, C and D: C yields a sure loss of $\$ 750,000$, and D is a lottery ticket yielding \$0 with 25 per cent probability and a loss of $\$ 1$ million with 75 per cent probability. Which would you prefer? This situation is not as absurd as it might seem at first glance; many financial decisions involve choosing between the lesser of two evils. In this case, most subjects choose $\mathrm{D}$, despite the fact that $\mathrm{D}$ is more risky than $\mathrm{C}$. When faced with two choices that both involve losses, individuals seem to be 'risk seeking', not risk averse as in the case of A versus B.

The fact that individuals tend to be risk averse in the face of gains and risk seeking in the face of losses can lead to some very poor financial decisions. To see why, observe that the combination of choices A and D is equivalent to a single lottery ticket yielding $\$ 240,000$ with 25 per cent probability and $-\$ 760,000$ with 75 per cent probability, whereas the combination of choices B and C is equivalent to a single lottery ticket yielding $\$ 250,000$ with 25 per cent probability and $-\$ 750,000$ with 75 per cent probability. The B and C combination has the same probabilities of gains and losses, but the gain is $\$ 10,000$ higher and the loss is $\$ 10,000$ lower. In other words, B and C is formally equivalent to A and D plus a sure profit of $\$ 10,000$. In light of this analysis, would you still prefer A and D?

A common response to this example is that it is contrived because the two pairs of investment opportunities were presented sequentially, not simultaneously. However, in a typical global financial institution the London office may be faced with choices A and B and the Tokyo office may be faced with choices C and D. Locally, it may seem as if there is no right or wrong answer - the choice between A and B or C and D seems to be simply a matter of personal risk preferences - but the globally consolidated financial statement for the entire institution will tell a very different story. From that perspective, there is a right and wrong answer, and the empirical and experimental evidence suggests that most individuals tend to select the wrong answer. Therefore, according to the behaviouralists, quantitative models of 
efficient markets - all of which are predicated on rational choice - are likely to be wrong as well.

\section{Impossibility of efficient markets}

Grossman and Stiglitz (1980) go even farther - they argue that perfectly informationally efficient markets are an impossibility for, if markets are perfectly efficient, there is no profit to gathering information, in which case there would be little reason to trade and markets would eventually collapse. Alternatively, the degree of market inefficiency determines the effort investors are willing to expend to gather and trade on information, hence a nondegenerate market equilibrium will arise only when there are sufficient profit opportunities, that is, inefficiencies, to compensate investors for the costs of trading and information gathering. The profits earned by these attentive investors may be viewed as 'economic rents' that accrue to those willing to engage in such activities. Who are the providers of these rents? Black (1986) gave us a provocative answer: 'noise traders', individuals who trade on what they consider to be information but which is, in fact, merely noise.

The supporters of the EMH have responded to these challenges by arguing that, while behavioural biases and corresponding inefficiencies do exist from time to time, there is a limit to their prevalence and impact because of opposing forces dedicated to exploiting such opportunities. A simple example of such a limit is the so-called 'Dutch book', in which irrational probability beliefs give rise to guaranteed profits for the savvy investor. Consider, for example, an event $E$, defined as 'the S\&P 500 index drops by five per cent or more next Monday', and suppose an individual has the following irrational beliefs: there is a 50 per cent probability that $E$ will occur, and a 75 per cent probability that $E$ will not occur. This is clearly a violation of one of the basic axioms of probability theory - the probabilities of two mutually exclusive and exhaustive events must sum to 1 - but many experimental studies have documented such violations among an overwhelming majority of human subjects.

These inconsistent subjective probability beliefs imply that the individual would be willing to take both of the following bets $B_{1}$ and $B_{2}$ :

$$
B_{1}=\left\{\begin{array}{rl}
\$ 1 & \text { if } E \\
-\$ 1 & \text { otherwise }
\end{array}, \quad B_{2}=\left\{\begin{aligned}
\$ 1 & \text { if } E^{c} \\
-\$ 3 & \text { otherwise }
\end{aligned}\right.\right.
$$

where $E^{c}$ denotes the event 'not $E$ '. Now suppose we take the opposite side of both bets, placing $\$ 50$ on $B_{1}$ and $\$ 25$ on $B_{2}$. If $E$ occurs, we lose $\$ 50$ on $B_{1}$ but gain $\$ 75$ on $B_{2}$, yielding a profit of $\$ 25$. If $E^{c}$ occurs, we gain $\$ 50$ on $B_{1}$ and lose $\$ 25$ on $B_{2}$, also yielding a 
profit of $\$ 25$. Regardless of the outcome, we have secured a profit of $\$ 25$, an 'arbitrage' that comes at the expense of the individual with inconsistent probability beliefs. Such beliefs are not sustainable, and market forces - namely, arbitrageurs such as hedge funds and proprietary trading groups - will take advantage of these opportunities until they no longer exist, that is, until the odds are in line with the axioms of probability theory. (Only when these axioms are satisfied is arbitrage ruled out. This was conjectured by Ramsey, 1926, and proved rigorously by de Finetti, 1937, and Savage, 1954.) Therefore, proponents of the classical EMH argue that there are limits to the degree and persistence of behavioural biases such as inconsistent probability beliefs, and substantial incentives for those who can identify and exploit such occurrences. While all of us are subject to certain behavioural biases from time to time, according to EMH supporters market forces will always act to bring prices back to rational levels, implying that the impact of irrational behaviour on financial markets is generally negligible and, therefore, irrelevant.

But this last conclusion relies on the assumption that market forces are sufficiently powerful to overcome any type of behavioural bias, or equivalently that irrational beliefs are not so pervasive as to overwhelm the capacity of arbitrage capital dedicated to taking advantage of such irrationalities. This is an empirical issue that cannot be settled theoretically, but must be tested through careful measurement and statistical analysis. The classic reference by Kindleberger (1989) - where a number of speculative bubbles, financial panics, manias, and market crashes are described in detail - suggests that the forces of irrationality can overwhelm the forces of arbitrage capital for months and, in several wellknown cases, years.

So what does this imply for the EMH?

\section{The current state of the EMH}

Given all of the theoretical and empirical evidence for and against the $\mathrm{EMH}$, what can we conclude? Amazingly, there is still no consensus among economists. Despite the many advances in the statistical analysis, databases, and theoretical models surrounding the EMH, the main result of all of these studies is to harden the resolve of the proponents of each side of the debate.

One of the reasons for this state of affairs is the fact that the EMH, by itself, is not a well-defined and empirically refutable hypothesis. To make it operational, one must specify additional structure, for example, investors' preferences or information structure. But then a test of the EMH becomes a test of several auxiliary hypotheses as well, and a rejection of 
such a joint hypothesis tells us little about which aspect of the joint hypothesis is inconsistent with the data. Are stock prices too volatile because markets are inefficient, or due to risk aversion, or dividend smoothing? All three inferences are consistent with the data. Moreover, new statistical tests designed to distinguish among them will no doubt require auxiliary hypotheses of their own which, in turn, may be questioned.

More importantly, tests of the EMH may not be the most informative means of gauging the efficiency of a given market. What is often of more consequence is the efficiency of a particular market relative to other markets - for example, futures vs. spot markets, auction vs. dealer markets. The advantages of the concept of relative efficiency, as opposed to the allor-nothing notion of absolute efficiency, are easy to spot by way of an analogy. Physical systems are often given an efficiency rating based on the relative proportion of energy or fuel converted to useful work. Therefore, a piston engine may be rated at 60 per cent efficiency, meaning that on average 60 per cent of the energy contained in the engine's fuel is used to turn the crankshaft, with the remaining 40 per cent lost to other forms of work, such as heat, light or noise.

Few engineers would ever consider performing a statistical test to determine whether or not a given engine is perfectly efficient - such an engine exists only in the idealized frictionless world of the imagination. But measuring relative efficiency - relative, that is, to the frictionless ideal - is commonplace. Indeed, we have come to expect such measurements for many household products: air conditioners, hot water heaters, refrigerators, and so on. Therefore, from a practical point of view, and in light of Grossman and Stiglitz (1980), the $\mathrm{EMH}$ is an idealization that is economically unrealizable, but which serves as a useful benchmark for measuring relative efficiency.

The desire to build financial theories based on more realistic assumptions has led to several new strands of literature, including psychological approaches to risk-taking behaviour (Kahneman and Tversky, 1979; Thaler, 1993; Lo, 1999), evolutionary game theory (Friedman, 1991), agent-based modelling of financial markets (Arthur et al., 1997; Chan et al., 1998), and direct applications of the principles of evolutionary psychology to economics and finance (Lo, 1999; 2002; 2004; 2005; Lo and Repin, 2002). Although substantially different in methods and style, these emerging sub-fields are all directed at new interpretations of the EMH. In particular, psychological models of financial markets focus on the the manner in which human psychology influences the economic decision-making process as an explanation of apparent departures from rationality. Evolutionary game theory studies the evolution and steady-state equilibria of populations of competing strategies in 
highly idealized settings. Agent-based models are meant to capture complex learning behaviour and dynamics in financial markets using more realistic markets, strategies, and information structures. And applications of evolutionary psychology provide a reconciliation of rational expectations with the behavioural findings that often seem inconsistent with rationality.

For example, in one agent-based model of financial markets (Farmer, 2002), the market is modelled using a non-equilibrium market mechanism, whose simplicity makes it possible to obtain analytic results while maintaining a plausible degree of realism. Market participants are treated as computational entities that employ strategies based on limited information. Through their (sometimes suboptimal) actions they make profits or losses. Profitable strategies accumulate capital with the passage of time, and unprofitable strategies lose money and may eventually disappear. A financial market can thus be viewed as a co-evolving ecology of trading strategies. The strategy is analogous to a biological species, and the total capital deployed by agents following a given strategy is analogous to the population of that species. The creation of new strategies may alter the profitability of pre-existing strategies, in some cases replacing them or driving them extinct.

Although agent-based models are still in their infancy, the simulations and related theory have already demonstrated an ability to understand many aspects of financial markets. Several studies indicate that, as the population of strategies evolves, the market tends to become more efficient, but this is far from the perfect efficiency of the classical EMH. Prices fluctuate in time with internal dynamics caused by the interaction of diverse trading strategies. Prices do not necessarily reflect 'true values'; if we view the market as a machine whose job is to set prices properly, the inefficiency of this machine can be substantial. Patterns in the price tend to disappear as agents evolve profitable strategies to exploit them, but this occurs only over an extended period of time, during which substantial profits may be accumulated and new patterns may appear.

\section{The adaptive markets hypothesis}

The methodological differences between mainstream and behavioural economics suggest that an alternative to the traditional deductive approach of neoclassical economics may be necessary to reconcile the EMH with its behavioural critics. One particularly promising direction is to view financial markets from a biological perspective and, specifically, within an evolutionary framework in which markets, instruments, institutions and investors interact and evolve dynamically according to the 'law' of economic selection. Under this view, 
financial agents compete and adapt, but they do not necessarily do so in an optimal fashion (see Farmer and Lo, 1999; Farmer, 2002; Lo, 2002; 2004; 2005).

This evolutionary approach is heavily influenced by recent advances in the emerging discipline of 'evolutionary psychology', which builds on the seminal research of E.O. Wilson (1975) in applying the principles of competition, reproduction, and natural selection to social interactions, yielding surprisingly compelling explanations for certain kinds of human behaviour, such as altruism, fairness, kin selection, language, mate selection, religion, morality, ethics and abstract thought (see, for example, Barkow, Cosmides and Tooby, 1992; Gigerenzer, 2000). 'Sociobiology' is the rubric that Wilson (1975) gave to these powerful ideas, which generated a considerable degree of controversy in their own right, and the same principles can be applied to economic and financial contexts. In doing so, we can fully reconcile the EMH with all of its behavioural alternatives, leading to a new synthesis: the adaptive markets hypothesis (AMH).

Students of the history of economic thought will no doubt recall that Thomas Malthus used biological arguments - the fact that populations increase at geometric rates whereas natural resources increase at only arithmetic rates - to arrive at rather dire economic consequences, and that both Darwin and Wallace were influenced by these arguments (see Hirshleifer, 1977, for further details). Also, Joseph Schumpeter's view of business cycles, entrepreneurs and capitalism have an unmistakeable evolutionary flavour to them; in fact, his notions of 'creative destruction' and 'bursts' of entrepreneurial activity are similar in spirit to natural selection and Eldredge and Gould's (1972) notion of ‘punctuated equilibrium'. More recently, economists and biologists have begun to explore these connections in several veins: direct extensions of sociobiology to economics (Becker, 1976; Hirshleifer, 1977); evolutionary game theory (Maynard Smith, 1982); evolutionary economics (Nelson and Winter, 1982); and economics as a complex system (Anderson, Arrow and Pines, 1988). And publications like the Journal of Evolutionary Economics and the Electronic Journal of Evolutionary Modeling and Economic Dynamics now provide a home for research at the intersection of economics and biology.

Evolutionary concepts have also appeared in a number of financial contexts. For example, Luo (1995) explores the implications of natural selection for futures markets, and Hirshleifer and Luo (2001) consider the long-run prospects of overconfident traders in a competitive securities market. The literature on agent-based modelling pioneered by Arthur et al. (1997), in which interactions among software agents programmed with simple heuristics are simulated, relies heavily on evolutionary dynamics. And at least two prominent 
practitioners have proposed Darwinian alternatives to the EMH. In a chapter titled 'The Ecology of Markets', Niederhoffer (1997, ch. 15) likens financial markets to an ecosystem with dealers as 'herbivores', speculators as 'carnivores', and floor traders and distressed investors as 'decomposers'. And Bernstein (1998) makes a compelling case for active management by pointing out that the notion of equilibrium, which is central to the $\mathrm{EMH}$, is rarely realized in practice and that market dynamics are better explained by evolutionary processes.

Clearly the time is now ripe for an evolutionary alternative to market efficiency.

To that end, in the current context of the EMH we begin, as Samuelson (1947) did, with the theory of the individual consumer. Contrary to the neoclassical postulate that individuals maximize expected utility and have rational expectations, an evolutionary perspective makes considerably more modest claims, viewing individuals as organisms that have been honed, through generations of natural selection, to maximize the survival of their genetic material (see, for example, Dawkins, 1976). While such a reductionist approach can quickly degenerate into useless generalities - for example, the molecular biology of economic behaviour - nevertheless, there are valuable insights to be gained from the broader biological perspective. Specifically, this perspective implies that behaviour is not necessarily intrinsic and exogenous, but evolves by natural selection and depends on the particular environmental through which selection occurs. That is, natural selection operates not only upon genetic material but also upon social and cultural norms in homo sapiens; hence Wilson's term 'sociobiology'.

To operationalize this perspective within an economic context, consider the idea of 'bounded rationality’ first espoused by Nobel-prize-winning economist Herbert Simon. Simon (1955) suggested that individuals are hardly capable of the kind of optimization that neoclassical economics calls for in the standard theory of consumer choice. Instead, he argued that, because optimization is costly and humans are naturally limited in their computational abilities, they engage in something he called 'satisficing', an alternative to optimization in which individuals make choices that are merely satisfactory, not necessarily optimal. In other words, individuals are bounded in their degree of rationality, which is in sharp contrast to the current orthodoxy - rational expectations - where individuals have unbounded rationality (the term 'hyper-rational expectations' might be more descriptive). Unfortunately, although this idea garnered a Nobel Prize for Simon, it had relatively little impact on the economics profession. (However, his work is now receiving greater attention, thanks in part to the growing behavioural literature in economics and finance. See, for example, Simon, 1982; 
Sargent, 1993; A. Rubinstein, 1998; Gigerenzer and Selten, 2001.) Apart from the sociological factors discussed above, Simon's framework was commonly dismissed because of one specific criticism: what determines the point at which an individual stops optimizing and reaches a satisfactory solution? If such a point is determined by the usual cost-benefit calculation underlying much of microeconomics (that is, optimize until the marginal benefits of the optimum equals the marginal cost of getting there), this assumes the optimal solution is known, which would eliminate the need for satisficing. As a result, the idea of bounded rationality fell by the wayside, and rational expectations has become the de facto standard for modelling economic behaviour under uncertainty.

An evolutionary perspective provides the missing ingredient in Simon's framework. The proper response to the question of how individuals determine the point at which their optimizing behaviour is satisfactory is this: such points are determined not analytically but through trial and error and, of course, natural selection. Individuals make choices based on past experience and their 'best guess' as to what might be optimal, and they learn by receiving positive or negative reinforcement from the outcomes. If they receive no such reinforcement, they do not learn. In this fashion, individuals develop heuristics to solve various economic challenges, and, as long as those challenges remain stable, the heuristics will eventually adapt to yield approximately optimal solutions to them.

If, on the other hand, the environment changes, then it should come as no surprise that the heuristics of the old environment are not necessarily suited to the new. In such cases, we observe 'behavioural biases' - actions that are apparently ill-advised in the context in which we observe them. But rather than labelling such behaviour 'irrational', it should be recognized that suboptimal behaviour is not unlikely when we take heuristics out of their evolutionary context. A more accurate term for such behaviour might be 'maladaptive'. The flopping of a fish on dry land may seem strange and unproductive, but under water the same motions are capable of propelling the fish away from its predators.

By coupling Simon's notion of bounded rationality and satisficing with evolutionary dynamics, many other aspects of economic behaviour can also be derived. Competition, cooperation, market-making behaviour, general equilibrium, and disequilibrium dynamics are all adaptations designed to address certain environmental challenges for the human species, and by viewing them through the lens of evolutionary biology we can better understand the apparent contradictions between the EMH and the presence and persistence of behavioural biases.

Specifically, the adaptive markets hypothesis can be viewed as a new version of the 
EMH, derived from evolutionary principles. Prices reflect as much information as dictated by the combination of environmental conditions and the number and nature of 'species' in the economy or, to use the appropriate biological term, the ecology. By 'species' I mean distinct groups of market participants, each behaving in a common manner. For example, pension funds may be considered one species; retail investors, another; market-makers, a third; and hedge-fund managers, a fourth. If multiple species (or the members of a single highly populous species) are competing for rather scarce resources within a single market, that market is likely to be highly efficient - for example, the market for 10-Year US Treasury Notes reflects most relevant information very quickly indeed. If, on the other hand, a small number of species are competing for rather abundant resources in a given market, that market will be less efficient - for example, the market for oil paintings from the Italian Renaissance. Market efficiency cannot be evaluated in a vacuum, but is highly context-dependent and dynamic, just as insect populations advance and decline as a function of the seasons, the number of predators and prey they face, and their abilities to adapt to an ever-changing environment.

The profit opportunities in any given market are akin to the amount of food and water in a particular local ecology - the more resources present, the less fierce the competition. As competition increases, either because of dwindling food supplies or an increase in the animal population, resources are depleted which, in turn, causes a population decline eventually, decreasing the level of competition and starting the cycle again. In some cases cycles converge to corner solutions, that is, certain species become extinct, food sources are permanently exhausted, or environmental conditions shift dramatically. By viewing economic profits as the ultimate food source on which market participants depend for their survival, the dynamics of market interactions and financial innovation can be readily derived.

Under the $\mathrm{AMH}$, behavioural biases abound. The origins of such biases are heuristics that are adapted to non-financial contexts, and their impact is determined by the size of the population with such biases versus the size of competing populations with more effective heuristics. During the autumn of 1998, the desire for liquidity and safety by a certain population of investors overwhelmed the population of hedge funds attempting to arbitrage such preferences, causing those arbitrage relations to break down. However, in the years prior to August 1998 fixed-income relative-value traders profited handsomely from these activities, presumably at the expense of individuals with seemingly 'irrational' preferences (in fact, such preferences were shaped by a certain set of evolutionary forces, and might be quite rational in other contexts). Therefore, under the $\mathrm{AMH}$, investment strategies undergo cycles 
of profitability and loss in response to changing business conditions, the number of competitors entering and exiting the industry, and the type and magnitude of profit opportunities available. As opportunities shift, so too will the affected populations. For example, after 1998 the number of fixed-income relative-value hedge funds declined dramatically - because of outright failures, investor redemptions, and fewer start-ups in this sector - but many have reappeared in recent years as performance for this type of investment strategy has improved.

Even fear and greed - the two most common culprits in the downfall of rational thinking according to most behaviouralists - are the product of evolutionary forces, adaptive traits that enhance the probability of survival. Recent research in the cognitive neurosciences and economics, now coalescing into the discipline known as 'neuroeconomics', suggests an important link between rationality in decision-making and emotion (Grossberg and Gutowski, 1987; Damasio, 1994; Elster, 1998; Lo and Repin, 2002; and Loewenstein, 2000), implying that the two are not antithetical but in fact complementary. For example, contrary to the common belief that emotions have no place in rational financial decision-making processes, Lo and Repin (2002) present preliminary evidence that physiological variables associated with the autonomic nervous system are highly correlated with market events even for highly experienced professional securities traders. They argue that emotional responses are a significant factor in the real-time processing of financial risks, and that an important component of a professional trader's skills lies in his or her ability to channel emotion, consciously or unconsciously, in specific ways during certain market conditions.

This argument often surprises economists because of the link between emotion and behavioural biases, but a more sophisticated view of the role of emotions in human cognition shows that they are central to rationality (see, for example, Damasio, 1994; Rolls, 1999). In particular, emotions are the basis for a reward-and-punishment system that facilitates the selection of advantageous behaviour, providing a numeraire for animals to engage in a 'costbenefit analysis' of the various actions open to them (Rolls, 1999, ch. 10.3). From an evolutionary perspective, emotion is a powerful adaptation that dramatically improves the efficiency with which animals learn from their environment and their past (see Damasio, 1994). These evolutionary underpinnings are more than simple speculation in the context of financial market participants. The extraordinary degree of competitiveness of global financial markets and the outsize rewards that accrue to the 'fittest' traders suggest that Darwinian selection - 'survival of the richest', to be precise - is at work in determining the typical profile of the successful trader. After all, unsuccessful traders are eventually eliminated from 
the population after suffering a certain level of losses.

The new paradigm of the AMH is still under development, and certainly requires a great deal more research to render it 'operationally meaningful' in Samuelson's sense. However, even at this early stage it is clear that an evolutionary framework is able to reconcile many of the apparent contradictions between efficient markets and behavioural exceptions. The former may be viewed as the steady-state limit of a population with constant environmental conditions, and the latter involves specific adaptations of certain groups that may or may not persist, depending on the particular evolutionary paths that the economy experiences. More specific implications may be derived through a combination of deductive and inductive inference - for example, theoretical analysis of evolutionary dynamics, empirical analysis of evolutionary forces in financial markets, and experimental analysis of decision-making at the individual and group level.

For example, one implication is that, to the extent that a relation between risk and reward exists, it is unlikely to be stable over time. Such a relation is determined by the relative sizes and preferences of various populations in the market ecology, as well as institutional aspects such as the regulatory environment and tax laws. As these factors shift over time, any risk-reward relation is likely to be affected. A corollary of this implication is that the equity risk premium is also time-varying and path-dependent. This is not so revolutionary an idea as it might first appear - even in the context of a rational expectations equilibrium model, if risk preferences change over time, then the equity risk premium must vary too. The incremental insight of the $\mathrm{AMH}$ is that aggregate risk preferences are not immutable constants, but are shaped by the forces of natural selection. For example, until recently US markets were populated by a significant group of investors who had never experienced a genuine bear market - this fact has undoubtedly shaped the aggregate risk preferences of the US economy, just as the experience since the bursting of the technology bubble in the early 2000s has affected the risk preferences of the current population of investors. In this context, natural selection determines who participates in market interactions; those investors who experienced substantial losses in the technology bubble are more likely to have exited the market, leaving a markedly different population of investors. Through the forces of natural selection, history matters. Irrespective of whether prices fully reflect all available information, the particular path that market prices have taken over the past few years influences current aggregate risk preferences. Among the three fundamental components of any market equilibrium - prices, probabilities, and preferences - preferences is clearly the most fundamental and least understood. Several large bodies of research have 
developed around these issues - in economics and finance, psychology, operations research (also called 'decision sciences') and, more recently, brain and cognitive sciences - and many new insights are likely to flow from synthesizing these different strands of research into a more complete understanding of how individuals make decisions (see Starmer, 2000, for an excellent review of this literature). Simon's (1982) seminal contributions to this literature are still remarkably timely and their implications have yet to be fully explored.

\section{Conclusions}

Many other practical insights and potential breakthroughs can be derived from shifting our mode of thinking in financial economics from the physical to the biological sciences. Although evolutionary ideas are not yet part of the financial mainstream, the hope is that they will become more commonplace as they demonstrate their worth - ideas are also subject to 'survival of the fittest'. No one has illustrated this principal so well as Harry Markowitz, the father of modern portfolio theory and a Nobel laureate in economics in 1990. In describing his experience as a Ph.D. student on the eve of his graduation, he wrote in his Nobel address (Markowitz, 1991, p. 476):

... [W]hen I defended my dissertation as a student in the Economics Department of the University of Chicago, Professor Milton Friedman argued that portfolio theory was not Economics, and that they could not award me a Ph.D. degree in Economics for a dissertation which was not Economics. I assume that he was only half serious, since they did award me the degree without long debate. As to the merits of his arguments, at this point I am quite willing to concede: at the time I defended my dissertation, portfolio theory was not part of Economics. But now it is.

In light of the sociology of the EMH controversy (see, for example, Lo, 2004), the debate is likely to continue. However, despite the lack of consensus in academia and industry, the ongoing dialogue has given us many new insights into the economic structure of financial markets. If, as Paul Samuelson has suggested, financial economics is the crown jewel of the social sciences, then the EMH must account for half the facets.

Andrew W. Lo

See also asset price anomalies; bounded rationality; financial market anomalies; information 
economics; rational expectations

I thank John Cox, Gene Fama, Bob Merton, and Paul Samuelson for helpful discussions.

\section{Bibliography}

Anderson, P. Arrow, K. and Pines, D.eds. 1988. The Economy as an Evolving Complex System. Reading, MA: Addison-Wesley Publishing Company.

Arthur, B. Holland, J. LeBaron, B. Palmer R. and P. Tayler. 1997. Asset pricing under endogenous expectations in an artificial stock market. In The Economy as an Evolving Complex System II, ed. B. Arthur, S. Durlauf, and D. Lane Reading, MA: Addison Wesley.

Ball, R. and Brown, P. 1968. An empirical evaluation of accounting income numbers. Journal of Accounting Research 6, 159-78.

Banz, R. 1981. The relationship between return and market value of common stock. Journal of Financial Economics 9, 3-18.

Barber, B. and Odean, T. 2001. Boys will be boys: gender, overconfidence, and common stock investment. Quarterly Journal of Economics 116, 261-29.

Barkow, J. Cosmides, L. and Tooby, J. 1992. The Adapted Mind: Evolutionary Psychology and the Generation of Culture. Oxford: Oxford University Press.

Basu, S. 1977. The investment performance of common stocks in relation to their priceearnings ratios: a test of the efficient market hypothesis. Journal of Finance 32, 663-82.

Becker, G. 1976. Altruism, egoism, and genetic fitness: economics and sociobiology. Journal of Economic Literature 14, 817-26.

Bell, D. 1982. Risk premiums for decision regret. Management Science 29, 1156-66.

Bernard, V. and Thomas, J. 1990. Evidence that stock prices do not fully reflect the implications of current earnings for future earnings. Journal of Accounting and Economics 13, 305-40.

Bernstein, P. 1998. Why the efficient market offers hope to active management. In Economics and Portfolio Strategy, 1 October. New York: Peter Bernstein, Inc.

Black, F. 1986. Noise. Journal of Finance 41, 529-44.

Black, F. and Scholes, M. 1973. Pricing of options and corporate liabilities. Journal of Political Economy 81, 637-54. 
Brown, S. Goetzmann, W. Ibbotson, R. and Ross, S. 1992. Survivorship bias in performance studies. Review of Financial Studies 5, 553-80.

Campbell, J. and Shiller, R. 1988. The dividend-price ratio and expectations of future dividends and discount factors. Review of Financial Studies 1, 195-228.

Chan, K. 1988. On the contrarian investment strategy. Journal of Business 61, 147-64.

Chan, L., Jegadeesh, N. and Lakonishok, J. 1996. Momentum strategies. Journal of Finance $51,1681-713$.

Chan, N., LeBaron, B., Lo, A. and Poggio, T. 1998. Information Dissemination and Aggregation in Asset Markets with Simple Intelligent Traders. Laboratory Technical Memorandum No. 1646. Cambridge, MA: MIT Artificial Intelligence.

Chopra, N. Lakonishok, J. and Ritter, J. 1992. Measuring Abnormal Performance: Do Stocks Overreact? Journal of Financial Economics 31, 235-86.

Cootner, P. 1962. Stock prices: random vs. systematic changes. Industrial Management Review 3, 24-45.

Cootner, P. 1964. The Random Character of Stock Market Prices. London: Risk Publications.

Copeland, T. and Mayers, D. 1982. The Value Line enigma (1965-1978): a case study of performance evaluation issues. Journal of Financial Economics 10, 289-322.

Cowles, A. 1960. A revision of previous conclusions regarding stock price behavior. Econometrica 28, 909-15.

Cowles, A. and Jones, H. 1937. Some a posteriori probabilities in stock market action. Econometrica 5, 280-294.

Damasio, A. 1994. Descartes’ Error: Emotion, Reason, and the Human Brain. New York: Avon Books.

Dawkins, R. 1976. The Selfish Gene. Oxford: Oxford University Press.

de Finetti, B. 1937. La Prévision: Ses Lois Logiques, Ses Sources Subjectives. Annales de l'Institut Henri Poincaré 7, 1-68. English translation in Studies in Subjective Probability, ed. H. Kyburg and H. Smokler. New York: John Wiley \& Sons, 1964.

DeBondt, W. and Thaler, R. 1985. Does the stock market overreact?. Journal of Finance 40, 793-807.

Eldredge, N. and Gould, S. 1972. Punctuated equilibria: an alternative to phyletic gradualism. In Models in Paleobiology, ed. T. Schopf. San Francisco: Freeman, Cooper.

Elster, J. 1998. Emotions and economic theory. Journal of Economic Literature 36, 47-74. Fama, E. 1963. Mandelbrot and the stable Paretian hypothesis. Journal of Business 36, 420- 
29.

Fama, E. 1965a. The behavior of stock market prices. Journal of Business 38, 34-105.

Fama, E. 1965b. Random walks in stock market prices. Financial Analysts Journal 21, 559.

Fama, E. 1970. Efficient capital markets: a review of theory and empirical work. Journal of Finance 25, 383-417.

Fama, E. and Blume, M. 1966. Filter rules and stock market trading profits. Journal of Business 39, 226-41.

Fama, E. and French, K.1988. Permanent and temporary components of stock prices. Journal of Political Economy 96, 246-73.

Farmer, D. 2002. Market force, ecology and evolution. Industrial and Corporate Change 11, 895-953.

Farmer, D. and Lo, A. 1999. Frontiers of finance: evolution and efficient markets. Proceedings of the National Academy of Sciences 96, 9991-2.

Fischoff, B. and Slovic, P. 1980. A little learning...: confidence in multicue judgment tasks. In Attention and Performance, VIII, ed. R. Nickerson Hillsdale, NJ: Erlbaum.

Flavin, M. 1983. Excess volatility in the financial markets: a reassessment of the empirical evidence. Journal of Political Economy 91, 929-56.

French, K. and Roll, R. 1986. Stock return variances: the arrival of information and the reaction of traders. Journal of Financial Economics 17, 5-26.

Friedman, D. 1991. Evolutionary games in economics. Econometrica 59, 637-66.

Gervais, S. and Odean, T. 2001. Learning to be overconfident. Review of Financial Studies $14,1-27$.

Gigerenzer, G. 2000, Adaptive Thinking: Rationality in the Real World. Oxford: Oxford University Press.

Gigerenzer, G. and Selten, R. 2001, Bounded Rational: The Adaptive Toolbox. Cambridge, MA: MIT Press.

Gilles, C. and LeRoy, S. 1991. Econometric aspects of the variance-bounds tests: a survey. Review of Financial Studies 4, 753-92.

Grossberg, S. and Gutowski, W. 1987. Neural dynamics of decision making under risk: affective balance and cognitive-emotional interactions. Psychological Review 94, 300-18.

Grossman, S. and Shiller, R. 1981. The determinants of the variability of stock market prices. American Economic Review 71, 222-7.

Grossman, S. and Stiglitz, J. 1980. On the impossibility of informationally efficient markets. 
American Economic Review 70, 393-408.

Hirshleifer, J. 1977. Economics from a biological viewpoint. Journal of Law and Economics 20, 1-52.

Hirshleifer, D. and Luo, G. 2001. On the survival of overconfident traders in a competitive securities market. Journal of Financial Markets 4, 73-84.

Huberman, G. and Regev, T. 2001. Contagious speculation and a cure for cancer: a nonevent that made stock prices soar. Journal of Finance 56, 387-96.

Jegadeesh, N. 1990. Evidence of predictable behavior of security returns. Journal of Finance 45, 881-98.

Jegadeesh, N. and Titman, S. 2001. Profitability of momentum strategies: an evaluation of alternative explanations. Journal of Finance 56, 699-720.

Kahneman, D. and Tversky, A. 1979. Prospect theory: an analysis of decision under risk. Econometrica 47, 263-91.

Keim, D. 1983. Size-related anomalies and stock return seasonality: further empirical evidence. Journal of Financial Economics 12, 13-32.

Kim, M., Nelson, C. and Startz, R. 1991. Mean reversion in stock prices? a reappraisal of the empirical evidence. Review of Economic Studies 58, 515-28.

Kindleberger, C. 1989. Manias, Panics, and Crashes: A History of Financial Crises. New York: Basic Books.

Kleidon, A. 1986. Variance bounds tests and stock price valuation models. Journal of Political Economy 94, 953-1001.

Laibson, D. 1997. Golden eggs and hyperbolic discounting. Quarterly Journal of Economics 62, 443-77.

Lakonishok, J. and Smidt, S. 1988. Are seasonal anomalies real? A ninety-year perspective. Review of Financial Studies 1, 403-25.

Lehmann, B. 1990. Fads, martingales, and market efficiency. Quarterly Journal of Economics 105, 1-28.

Leroy, S. 1973. Risk aversion and the martingale property of stock returns. International Economic Review 14, 436-46.

LeRoy, S. and Porter, R.1981. The present value relation: tests based on variance bounds. Econometrica 49, 555-74.

Lichtenstein, S., Fischoff, B. and Phillips, L. 1982. Calibration of probabilities: the state of the art to 1980. In Judgment Under Uncertainty: Heuristics and Biases, ed. D. Kahneman, P. Slovic and A. Tversky. Cambridge: Cambridge University Press. 
Lo, A. 1991. Long-term memory in stock market prices. Econometrica 59, 1279-313.

Lo, A., ed. 1997. Market Efficiency: Stock Market Behavior in Theory and Practice, 2 vols. Cheltenham: Edward Elgar Publishing Company.

Lo, A. 1999. The three P's of total risk management. Financial Analysts Journal 55, 87129.

Lo, A. 2001. Risk management for hedge funds: introduction and overview. to appear in Financial Analysts Journal 57, 16-33.

Lo, A. 2002. Bubble, rubble, finance in trouble? Journal of Psychology and Financial Markets 3, 76-86.

Lo, A. 2004. The adaptive markets hypothesis: market efficiency from an evolutionary perspective. Journal of Portfolio Management 30, 15-29.

Lo, A. 2005. Reconciling efficient markets with behavioral finance: the adaptive markets hypothesis. Journal of Investment Consulting 7, 21-44.

Lo, A. and MacKinlay, C. 1988. Stock market prices do not follow random walks: evidence from a simple specification test. Review of Financial Studies 1, 41-66.

Lo, A. and MacKinlay, C. 1990a. An econometric analysis of nonsynchronous trading. Journal of Econometrics 45, 181-212.

Lo, A. and MacKinlay, C. 1990b. Data snooping biases in tests of financial asset pricing models. Review of Financial Studies 3, 431-68.

Lo, A. and MacKinlay, C. 1990c. When are contrarian profits due to stock market overreaction? Review of Financial Studies 3, 175-206.

Lo, A. and MacKinlay, C. 1999. A Non-Random Walk Down Wall Street. Princeton, NJ: Princeton University Press.

Lo, A. and Repin, D. 2002. The psychophysiology of real-time financial risk processing. Journal of Cognitive Neuroscience 14, 323-39.

Loewenstein, G. 2000. Emotions in economic theory and economic behavior. American Economic Review 90, 426-32.

Lucas, R. 1978. Asset prices in an exchange economy. Econometrica 46, 1429-46.

Luo, G. 1995. Evolution and market competition. Journal of Economic Theory 67, 223-50.

Markowitz, H. 1991. Foundations of portfolio theory. Journal of Finance 46, 469-77.

Marsh, T. andMerton, R. 1986. Dividend variability and variance bounds tests for the rationality of stock market prices. American Economic Review 76, 483-98.

Maynard Smith, J. 1982, Evolution and the Theory of Games. Cambridge: Cambridge University Press. 
Merton, R. 1973. Theory of rational option pricing. Bell Journal of Economics and Management Science 4, 141-83.

Merton, R. 1987. On the current state of the stock market rationality hypothesis. In Macroeconomics and Finance: Essays in Honor of Franco Modigliani, ed. R. Dornbusch, S. Fischer and J. Bossons. Cambridge, MA: MIT Press.

Michener, R. 1982. Variance bounds in a simple model of asset pricing. Journal of Political Economy 90, 166-75.

Nelson, R. and Winter, S. 1982. An Evolutionary Theory of Economic Change. Cambridge, MA: Belknap Press of Harvard University Press.

Niederhoffer, V. 1997. Education of a Speculator. New York: John Wiley \& Sons.

Odean, T. 1998. Are investors reluctant to realize their losses?. Journal of Finance 53, 1775-98.

Osborne, M. 1959. Brownian motion in the stock market. Operations Research 7, 145-73.

Poterba, J. and Summers, L. 1988. Mean reversion in stock returns: evidence and implications. Journal of Financial Economics 22, 27-60.

Ramsey, F. 1926. Truth and probability. In Foundations of Mathematics and Other Logical Essays, ed. R. Braithwaite. New York: Harcourt Brace \& Co.

Richardson, M. 1993. Temporary components of stock prices: a skeptic's view. Journal of Business and Economics Statistics 11, 199-207.

Roberts, H. 1959. Stock-market 'patterns' and financial analysis: methodological suggestions. Journal of Finance 14, 1-10.

Roberts, H. 1967. Statistical versus clinical prediction of the stock market. Unpublished manuscript, Center for Research in Security Prices, University of Chicago.

Roll, R. 1983. Vas is das? The turn-of-the-year effect and the return premia of small firms. Journal of Portfolio Management 9, 18-28.

Roll, R. 1984. Orange juice and weather. American Economic Review 74, 861-80.

Rolls, E. 1999. The Brain and Emotion. Oxford: Oxford University Press.

Rosenberg, B., Reid, K. and Lanstein, R. 1985. Persuasive evidence of market inefficiency. Journal of Portfolio Management 11, 9-17.

Rozeff, M. and Kinney, W., Jr. 1976. Capital market seasonality: the case of stock returns. Journal of Financial Economics 3, 379-402.

Rubinstein, A. 1998. Modeling Bounded Rationality. Cambridge, MA: MIT Press.

Rubinstein, M. 1976. The valuation of uncertain income streams and the pricing of options. Bell Journal of Economics 7, 407-25. 
Samuelson, P. 1947. Foundations of Economics Analysis. Cambridge, MA: Harvard University Press.

Samuelson, P. 1965. Proof that properly anticipated prices fluctuate randomly. Industrial Management Review 6, 41-9.

Sargent, T. 1993. Bounded Rationality in Macroeconomics. Oxford: Clarendon Press.

Savage, L. 1954. Foundations of Statistics. New York: John Wiley \& Sons.

Schumpeter, J. 1939. Business Cycles: A Theoretical, Historical, And Statistical Analysis of the Capitalist Process. New York: McGraw-Hill.

Shefrin, M. and Statman, M. 1985. The disposition to sell winners too early and ride losers too long: theory and evidence. Journal of Finance 40, 777-90.

Shiller, R. 1981. Do stock prices move too much to be justified by subsequent changes in dividends? American Economic Review 71, 421-36.

Simon, H. 1955. A behavioral model of rational choice. Quarterly Journal of Economics 69, 99-118.

Simon, H. 1982. Models of Bounded Rationality, 2 vols. Cambridge, MA: MIT Press.

Starmer, C. 2000. Developments in non-expected utility theory: the hunt for a descriptive theory of choice under risk. Journal of Economic Literature 38, 332-82.

Thaler, R., ed. 1993, Advances in Behavioral Finance. New York: Russell Sage Foundation.

Tversky, A. and Kahneman, D.1981. The framing of decisions and the psychology of choice. Science 211, 453-8.

Wilson, E. 1975, Sociobiology: The New Synthesis. Cambridge, MA: Belknap Press of Harvard University Press. 